\title{
New findings on exponential convergence of a Nicholson's blowflies model with proportional delay
}

\author{
Changjin $\mathrm{Xu}^{1 *}$, Peiluan $\mathrm{Li}^{2}$ and Shuai Yuan ${ }^{3}$
}

"Correspondence: xcj403@126.com 1 Guizhou Key Laboratory of Economics System Simulation, Guizhou University of Finance and Economics, Guiyang, P.R. China Full list of author information is available at the end of the article

\begin{abstract}
We deal with Nicholson's blowflies model with proportional delays. Employing the differential inequality theory, we give a new sufficient condition that guarantees the exponential convergence of all solutions of Nicholson's blowflies model with proportional delays. Numerical simulations are put into effect to examine our theoretical findings. The derived results of this manuscript are innovative and complement some known investigations.
\end{abstract}

MSC: $34 \mathrm{C} 27 ; 34 \mathrm{D} 23$

Keywords: Nicholson; s blowflies model; Exponential convergence; Proportional delay

\section{Introduction}

To describe the periodic oscillation in Nicholson's classic experiments [1] with the Australian sheep blowfly, Lucilia cuprina, Gurney et al. [2] put up the following Nicholson's blowflies model:

$$
\dot{w}(t)=-d w(t)+b w(t-\vartheta) e^{-\gamma x(t-\vartheta)},
$$

where $b$ is the maximum per capita daily egg production rate, $\frac{1}{\gamma}$ is the size at which the blowfly population reproduces at its maximum rate, $d$ is the per capita daily adult death rate, and $\vartheta$ is the generation time. Due to the immense application of Nicholson's blowflies model in biology, model (1.1) and its modifications have been extensively discussed by lots of authors (see, e.g., [3-6] and the references therein). Noticing the periodic change of real environment, many scholars [7-9] generalized model (1.1) into the following Nicholson's blowflies model:

$$
\dot{w}(t)=-d(t) w(t)+\sum_{j=1}^{m} b_{j}(t) w\left(t-\vartheta_{j}(t)\right) e^{-\gamma_{j}(t) w\left(t-\vartheta_{j}(t)\right)},
$$

where $m$ is a positive integer, $d: R \rightarrow R$ and $b_{j}, \gamma_{j}, \vartheta_{j}: R \rightarrow[0,+\infty), j=1,2, \ldots, m$, are bounded continuous functions, and $w(t)$ is the size of the population at time $t$. Noting

(c) The Author(s) 2019. This article is distributed under the terms of the Creative Commons Attribution 4.0 International License (http://creativecommons.org/licenses/by/4.0/), which permits unrestricted use, distribution, and reproduction in any medium, provided you give appropriate credit to the original author(s) and the source, provide a link to the Creative Commons license, and indicate if changes were made. 
that the exponential convergent rate can be unveiled [10-29], Long [30] investigated the exponential convergence of model (1.2).

Some researchers think that time delays appearing in many biological models are proportional; in other words, the proportional delay function takes the form $\vartheta(t)=t-a t$ $(0<a<1$ is a constant). In objective world, proportional delay plays a key role in numerous areas such as web quality, current collection [31], biological systems and many nonlinear models [32,33], electrodynamics [34], and probability principle [35]. So it is valuable to study the global exponential convergence of Nicholson's blowflies model with proportional delays. But so far there are no manuscripts about the global exponential convergence of Nicholson's blowflies model with proportional delays.

Stimulated by the above analysis, it is important for us to analyze the global exponential convergence on Nicholson's blowflies model with proportional delays. In this paper, we focus on the following Nicholson's blowflies model with proportional delays:

$$
\dot{w}(t)=-d(t) w(t)+\sum_{j=1}^{m} b_{j}(t) w\left(a_{j} t\right) e^{-\gamma_{j}(t) w\left(a_{j} t\right)},
$$

where $m$ is a positive integer, $d: R \rightarrow R$ and $b_{j}, \gamma_{j}, \vartheta_{j}: R \rightarrow[0,+\infty), j=1,2, \ldots, m$, are bounded continuous functions, $a_{j}$ is the proportional delay factor such that $0<a_{j}<1$, $a_{j} t=t-\left(1-a_{j}\right) t$, and $\left(1-a_{j}\right) t \rightarrow+\infty$ as $t \rightarrow+\infty$.

The initial condition of model (1.3) takes the form

$$
w(s)=\psi(s), \quad s \in\left[a_{0} t_{0}, t_{0}\right], t_{0}>0,
$$

where $a_{0}=\min _{i=1,2, \ldots, m}\left\{a_{i}\right\}$, and $\psi$ is a real-valued continuous function on $\left[a_{0} t_{0}, t_{0}\right]$.

For convenience, we denote $l^{+}=\sup _{t \in\left[t_{0},+\infty\right)}|l(t)|$ and $l^{-}=\inf _{t \in\left[t_{0},+\infty\right)}|l(t)|$ for a bounded continuous function $l$ on $\left[t_{0},+\infty\right)$.

Throughout this paper, we also make the following assumptions:

(K1) There exist a bounded continuous function: $d^{*}:\left[t_{0},+\infty\right) \rightarrow(0,+\infty)$ and a positive constant $\mu$ such that $e^{-\int_{s}^{t} d(\theta) d \theta} \leq \mu e^{-\int_{s}^{t} d^{*}(\theta) d \theta}$ for all $t, s \in R$ and $t-s \geq 0$.

(K2) $\sup _{t \geq t_{0}}\left\{-d^{*}(t)+\mu \sum_{j=1}^{m}\left|b_{j}(t)\right|\right\}<0$.

(K3) $m a>1$, where $a=\max _{1 \leq i \leq m}\left\{a_{i}\right\}$.

The key task of this paper is finding a sufficient condition that ensures the global exponential convergence of all solutions of (1.3). The key contributions of this paper are the following: (i) For the first time, the new Nicholson's blowflies model with proportional delays is presented; (ii) A new sufficient condition that guarantees the global exponential convergence of Nicholson's blowflies model with proportional delays is established; (iii) Until now, the global exponential convergence for Nicholson's blowflies model with proportional delays has not been studied.

\section{Main findings}

Now we will discuss the global exponential convergence of model (1.3)

Lemma 2.1 Let $d^{*-}>0$ and $\sigma \geq 0$ be constants such that

$$
\int_{s}^{t}\left(d^{*}(v)-d(v)\right) d v \leq \sigma \quad \text { for all } t, s \in R \text { and } t-s \geq 0 .
$$


Then for any $t_{0} \in R$, the solution $w\left(t ; t_{0}, \psi\right)$ of system (1.3) with the initial value (1.4) satisfies $w\left(t ; t_{0}, \psi\right)>0$ for all $t \in\left[t_{0}, \eta(\psi)\right)$ and $\eta(\psi)=+\infty$, where $\left[t_{0}, \eta(\psi)\right)$ is the maximal right interval of the existence of a solution $w\left(t ; t_{0}, \psi\right)$.

In view of the proof of Lemma 2.1 in Long [30], we can easily prove Lemma 2.1.

Theorem 2.1 For system (1.3), under the assumptions of Lemma 2.1, if (K1)-(K3) hold, then there exists a constant $\xi>0$ such that $w(t)=O\left(e^{-\xi t}\right)$ as $t \rightarrow+\infty$.

Proof Assume that $w(t)$ is an arbitrary solution of model (1.3). By (1.3) we have

$$
\dot{w}(t)+d(t) w(t)=\sum_{j=1}^{m} b_{j}(t) w\left(a_{j} t\right) e^{-\gamma_{j}(t) w\left(a_{j} t\right)} .
$$

Define the continuous function

$$
\Phi(\omega)=\sup _{t \geq t_{0}}\left\{\omega-d^{*}(t)+\mu\left[\sum_{j=1}^{m}\left|b_{j}(t)\right|+\omega\right]\right\}, \quad \omega \in[0,+\infty) .
$$

It follows from (K2) that

$$
\Phi(0)=\sup _{t \geq t_{0}}\left\{-d^{*}(t)+\mu\left[\sum_{j=1}^{m}\left|b_{j}(t)\right|\right]\right\}<0 .
$$

In view of the continuity of $\Phi(\omega)$, we can choose a constant $\xi \in\left(0, \inf _{t \geq t_{0}} d^{*}(t)\right)$ such that

$$
\Phi(\xi)=\sup _{t \geq t_{0}}\left\{\xi-d^{*}(t)+\mu\left[\sum_{j=1}^{m}\left|b_{j}(t)\right|+\xi\right]\right\}<0 .
$$

Let

$$
\|\psi\|_{\varrho}=\max _{t \in\left[a_{0} t_{0}, t_{0}\right]}|\psi(t)|
$$

For all $\epsilon>0$, we get

$$
|w(t)|<\left(\|\psi\|_{\varrho}+\epsilon\right) e^{-\xi\left(t-t_{0}\right)}<P\left(\|\psi\|_{\varrho}+\epsilon\right) e^{-\xi\left(t-t_{0}\right)}
$$

for $t \in\left[a_{0} t_{0}, t_{0}\right]$, where $P>\mu+1$. We will further prove that

$$
|w(t)|<P\left(\|\psi\|_{\varrho}+\epsilon\right) e^{-\xi\left(t-t_{0}\right)}
$$

fir $t \geq t_{0}$. Otherwise, there exists $t^{*}>t_{0}$ such that

$$
\left|w\left(t^{*}\right)\right|=P\left(\|\psi\|_{\varrho}+\epsilon\right) e^{-\xi\left(t^{*}-t_{0}\right)}
$$

and

$$
|w(t)|<P\left(\|\psi\|_{\varrho}+\epsilon\right) e^{-\xi\left(t-t_{0}\right)}
$$


for $t \in\left[a_{0} t_{0}, t^{*}\right]$. Note that

$$
\dot{w}(s)+d(t) w(s)=\sum_{j=1}^{m} b_{j}(s) w\left(a_{j} s\right) e^{-\gamma_{j}(s) w\left(a_{j} s\right)}
$$

for $s \in\left[t_{0}, t\right]$ and $t \in\left[t_{0}, t^{*}\right]$. By $(2.10)$ we get

$$
w(t)=w\left(t_{0}\right) e^{-\int_{t_{0}}^{t} d(v) d v}+\int_{t_{0}}^{t} e^{-\int_{s}^{t} d(v) d v}\left[\sum_{j=1}^{m} b_{j}(s) w\left(a_{j} s\right) e^{-\gamma_{j}(s) w\left(a_{j} s\right)}\right] d s, t \in\left[t_{0}, t^{*}\right] .
$$

By (2.4) and (K3) we have

$$
\begin{aligned}
& |w(t)|=\left|w\left(t_{0}\right) e^{-\int_{t_{0}}^{t} d(v) d v}+\int_{t_{0}}^{t} e^{-\int_{s}^{t} d(v) d v}\left[\sum_{j=1}^{m} b_{j}(s) w\left(a_{j} s\right) e^{-\gamma_{j}(s) w\left(a_{j} s\right)}\right] d s\right| \\
& \leq\left(\|\psi\|_{\varrho}+\epsilon\right) \mu e^{-\int_{t_{0}}^{t^{*}} d^{*}(v) d v}+\int_{t_{0}}^{t^{*}} e^{-\int_{s}^{t^{*}} d^{*}(v) d v} \mu\left[\sum_{j=1}^{m}\left|b_{j}(s)\right|\left|w\left(a_{j} s\right)\right|\right] d s \\
& \leq\left(\|\psi\|_{\varrho}+\epsilon\right) \mu e^{-\int_{t_{0}}^{t^{*}} d^{*}(v) d v} \\
& +\int_{t_{0}}^{t^{*}} e^{-\int_{s}^{t^{*}} d^{*}(v) d v} \mu\left[\sum_{j=1}^{m}\left|b_{j}(s)\right| P\left(\|\psi\|_{\varrho}+\epsilon\right) e^{-\xi\left(a_{j} s-t_{0}\right)}\right] d s \\
& \leq\left(\|\psi\|_{\varrho}+\epsilon\right) \mu e^{-\int_{t_{0}}^{t^{*}} d^{*}(v) d v}+\int_{t_{0}}^{t^{*}} e^{-\int_{s}^{t^{*}} d^{*}(v) d v} e^{-\xi\left(s-t_{0}\right)}\left(d^{*}(s)-\xi\right) d s \\
& \times e^{-\xi\left(t^{*}-t_{0}\right)} P\left(\|\psi\|_{\varrho}+\epsilon\right) \\
& =\left(\|\psi\|_{\varrho}+\epsilon\right) e^{-\xi\left(t^{*}-t_{0}\right)} \mu e^{-\int_{t_{0}}^{t^{*}}\left(d^{*}(v)-\xi\right) d v}+\int_{t_{0}}^{t^{*}} e^{-\int_{s}^{t^{*}}\left(d^{*}(v)-\xi\right) d v}\left(d^{*}(s)-\xi\right) d s \\
& \times e^{-\xi\left(t^{*}-t_{0}\right)} P\left(\|\varphi\|_{\varrho}+\epsilon\right) \\
& =P\left(\|\psi\|_{\varrho}+\epsilon\right) e^{-\xi\left(t^{*}-t_{0}\right)}\left[\frac{e^{-\int_{t_{0}}^{t^{*}}\left(d^{*}(v)-\xi\right) d v} \mu}{P}+1-e^{-\int_{t_{0}}^{t^{*}}\left(d^{*}(v)-\xi\right) d v}\right] \\
& =P\left(\|\psi\|_{\varrho}+\epsilon\right) e^{-\xi\left(t^{*}-t_{0}\right)}\left[\left(\frac{\kappa}{P}-1\right) e^{-\int_{t_{0}}^{t^{*}}\left(d^{*}(v)-\xi\right) d v}+1\right] \\
& <P\left(\|\psi\|_{\varrho}+\epsilon\right) e^{-\xi\left(t^{*}-t_{0}\right)},
\end{aligned}
$$

which contradicts (2.8). Then (2.7) is true. Thus $w(t)=O\left(e^{-\xi t}\right)$ as $t \rightarrow+\infty$. The theorem is proved.

Remark 2.1 In $[36,37]$ the authors dealt with neural networks with proportional delays, but they did not consider the global exponential convergence of involved models. In [10, 38 ] the authors studied the exponential convergence of neural networks with proportional delays, but they did not investigate Nicholson's blowflies models. In this paper, we study the global exponential convergence of Nicholson's blowflies model with proportional delays. All the derived results in [10,36-38] cannot be applied to model (1.3) to obtain the global exponential convergence of system (1.3). So far, no results about the global exponential convergence of Nicholson's blowflies model with proportional delays are reported. 


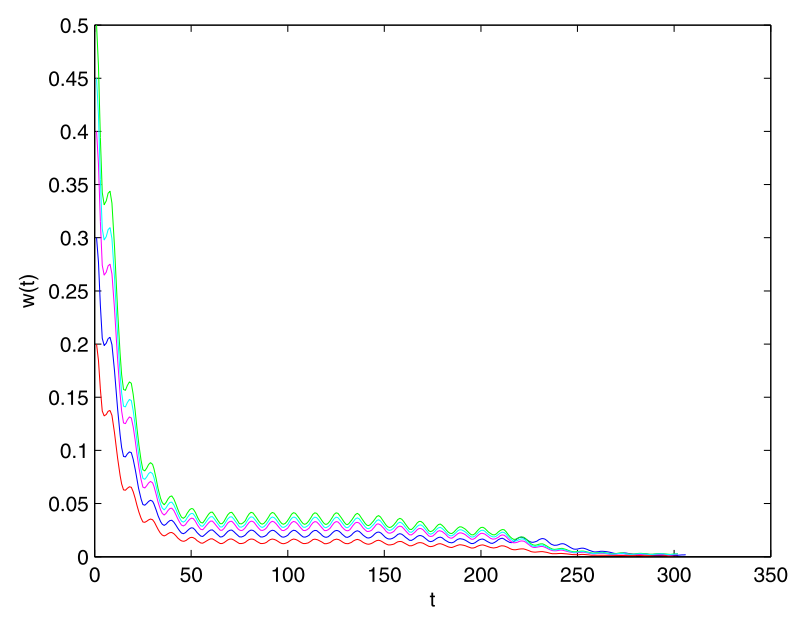

Figure 1 The relation of $t$ and $w(t)$. The initial values are $w_{0}=0.2,0.3,0.5,0.4,0.45$

Therefore our findings on the global exponential convergence of Nicholson's blowflies model with proportional delays are essentially innovative and supplement earlier publications to a certain extent.

\section{Example}

Consider the model

$$
\dot{w}(t)=-d(t) w(t)+\sum_{j=1}^{2} b_{j}(t) w\left(a_{j} t\right) e^{-\gamma_{j}(t) w\left(a_{j} t\right)},
$$

where $d(t)=0.2(1+0.5 \sin t), b_{1}(t)=0.07+0.07|\cos \sqrt{5 t}|, b_{2}(t)=0.05+0.05|\sin \sqrt{5 t}|$, $\gamma_{1}(t)=1+0.1|\cos \sqrt{3 t}|, \gamma_{2}(t)=1+0.1|\sin \sqrt{3 t}|, a_{1}=0.1, a_{2}=0.6$ Then $d^{*}(t)=0.2$ and $\mu=e^{\frac{1}{5}}$, Let $\sigma=\frac{1}{200}$. Then $e^{-\int_{s}^{t} d(\theta) d \theta} \leq e^{\frac{1}{5}} e^{-(t-s)}, t \geq s$, and $\int_{s}^{t}\left(d^{*}(v)-d(v)\right) d v \leq \sigma$, $\sup _{t \geq t_{0}}\left\{-d^{*}(t)+\mu \sum_{j=1}^{2}\left|b_{j}(t)\right|\right\} \approx-0.6052<0$. Thus all the conditions in Theorem 2.1 are satisfied, and all solutions of model (3.1) converge exponentially to $(0,0)^{T}$. This fact is shown in Fig. 1.

\section{Conclusions}

Exponential convergence is an important dynamical behavior of differential dynamical systems. During the past decades, many researchers payed much attention to it. In this paper, we have discussed Nicholson's blowflies model with proportional delays. By means of the differential inequality knowledge, we derived a sufficient criterion ensuring the exponential convergence of all solutions for Nicholson's blowflies model with proportional delays. The sufficiency criterion can be easily checked by simple computation. Up to now, there are no papers that focus on the exponential convergence of Nicholson's blowflies model with proportional delays, which shows that the results derived in this paper are new and extend earlier publications to some extent. 
of Guizhou Province ([2017]039), Project of Key Laboratory of Guizhou Province with Financial and Physical Features ([2017]004) and Hunan Provincial Key Laboratory of Mathematical Modeling and Analysis in Engineering (Changsha University of Science \& Technology) (2018MMAEZD21), University Science and Technology Top Talents Project of Guizhou Province (KY[2018]047), and Guizhou University of Finance and Economics (2018XZD01). The authors would like to thank the referees and the editor for helpful suggestions incorporated into this paper.

\section{Funding}

The work is supported by National National Natural Science Foundation of China (No. 61673008), Project of High-level Innovative Talents of Guizhou Province ([2016]5651), Major Research Project of The Innovation Group of The Education Department of Guizhou Province ([2017]039), Innovative Exploration Project of Guizhou University of Finance and Economics ([2017]5736-015), Project of Key Laboratory of Guizhou Province with Financial and Physical Features ([2017]004), Hunan Provincial Key Laboratory of Mathematical Modeling and Analysis in Engineering (Changsha University of Science \& Technology) (2018MMAEZD21), University Science and Technology Top Talents Project of Guizhou Province (KY[2018]047), and Guizhou University of Finance and Economics (2018XZD01).

\section{Competing interests}

The authors declare that they have no competing interests.

\section{Authors' contributions}

All authors have read and approved the final manuscript.

\section{Author details}

'Guizhou Key Laboratory of Economics System Simulation, Guizhou University of Finance and Economics, Guiyang,

P.R. China. ${ }^{2}$ School of Mathematics and Statistics, Henan University of Science and Technology, Luoyang, P.R. China.

${ }^{3}$ School of Mathematics and Statistics, Central South University, Changsha, P.R. China.

\section{Publisher's Note}

Springer Nature remains neutral with regard to jurisdictional claims in published maps and institutional affiliations.

Received: 26 May 2019 Accepted: 17 July 2019 Published online: 27 August 2019

\section{References}

1. Nicholson, A.: An outline of the dynamics of animal populations. Aust. J. Zool. 2(1), 19-65 (1954)

2. Gurney, W., Blythe, S., Nisbet, R.: Nicholson's blowflies revised. Nature 287, 17-21 (1980)

3. Yao, Z.J.: Existence and exponential stability of the unique positive almost periodic solution for impulsive Nicholson's blowflies model with linear harvesting term. Appl. Math. Model. 39(23-24), 7124-7133 (2015)

4. Chérif, F.: Pseudo almost periodic solution of Nicholson's blowflies model with mixed delays. Appl. Math. Model. 39(17), 5152-5163 (2015)

5. Duan, L., Fang, X.W., Huang, C.X.: Global exponential convergence in a delayed almost periodic Nicholson's blowflies model with discontinuous harvesting. Math. Methods Appl. Sci. 41(5), 1954-1965 (2018)

6. Huang, C.X., Zhang, H., Huang, L.H.: Almost periodicity analysis for a delayed Nicholson's blowflies model with nonlinear density-dependent mortality term. Commun. Pure Appl. Anal. 18(6), 3337-3349 (2019)

7. Amster, P., Déboli, A.: Existence of positive T-periodic solutions of a generalized Nicholson's blowflies model with a nonlinear harvesting term. Appl. Math. Lett. 25, 1203-1207 (2012)

8. Berezansky, L., Braverman, E.: On the exponentially stability of a linear delay differential equation with an oscillating coefficient. Appl. Math. Lett. 22, 1833-1837 (2009)

9. Berezansky, L., Braverman, E., Idels, L.: Nicholson's blowflies differential equations revised: main results and open problems. Appl. Math. Model. 34, 1405-1417 (2010)

10. Yu, Y.H.: Global exponential convergence for a class of HCNNs with neutral time-proportional delays. Appl. Math. Comput. 285, 1-7 (2016)

11. Yao, L.G.: Global exponential convergence of neutral type shunting inhibitory cellular neural networks with $D$ operator. Neural Process. Lett. 45, 401-409 (2017)

12. Jian, J.G., Wan, P.: Global exponential convergence of generalized chaotic systems with multiple time-varying and finite distributed delays. Phys. A, Stat. Mech. Appl. 431, 152-165 (2015)

13. Liu, B.W.: Global exponential convergence of non-autonomous cellular neural networks with multi-proportional delays. Neurocomputing 191, 352-355 (2016)

14. Wu, A.L., Zeng, Z.G., Zhang, J.N.: Global exponential convergence of periodic neural networks with time-varying delays. Neurocomputing 78(1), 149-154 (2012)

15. Jiang, A.l: Exponential convergence for shunting inhibitory cellular neural networks with oscillating coefficients in leakage terms. Neurocomputing 165, 159-162 (2015)

16. Duan, L., Huang, C.X.: Existence and global attractivity of almost periodic solutions for a delayed differential neoclassical growth model. Math. Methods Appl. Sci. 40(3), 814-822 (2017)

17. Chen, S.T., Tang, X.H.: Improved results for Klein-Gordon-Maxwell systems with general nonlinearity. Discrete Contin. Dyn. Syst., Ser. A 38(5), 2333-2348 (2018)

18. Chen, S.T., Tang, X.H.: Geometrically distinct solutions for Klein-Gordon-Maxwell systems with super-linear nonlinearities. Appl. Math. Lett. 90, 188-193 (2019)

19. Tang, X.H., Chen, S.T.: Ground state solutions of Nehari-Pohozaev type for Kirchhoff-type problems with general potentials. Calc. Var. Partial Differ. Equ. 56(4), 1-25 (2017)

20. Tang, X.H., Chen, S.T.: Ground state solutions of Schrödinger-Poisson systems with variable potential and convolution nonlinearity. J. Math. Anal. Appl. 473(1), 87-111 (2019) 
21. Jia, J., Huang, X., Li, Y.X., Cao, J.D., Ahmed, A.: Global stabilization of fractional-order memristor-based neural networks with time delay. IEEE Trans. Neural Netw. Learn. Syst. (2019). https://doi.org/10.1109/TNNLS.2019.2915353

22. Fan, Y., Huang, X., Li, Y., Xia, J., Chen, G.: Aperiodically intermittent control for quasi-synchronization of delayed memristive neural networks: an interval matrix and matrix measure combined method. IEEE Trans. Syst. Man Cybern. Syst. (2019). https://doi.org/10.1109/TSMC.2018.2850157

23. Fan, Y.J., Huang, X., Shen, H., Cao, J.D.: Switching event-triggered control for global stabilization of delayed memristive neural networks: an exponential attenuation scheme. Neural Netw. 117, 216-224 (2019)

24. Wang, X.H., Wang, Z., Shen, H.: Dynamical analysis of a discrete-time SIS epidemic model on complex networks. Appl. Math. Lett. 94, 292-299 (2019)

25. Fan, Y.J., Huang, X., Wang, Z., Li, Y.X.: Nonlinear dynamics and chaos in a simplified memristor-based fractional-order neural network with discontinuous memductance function. Nonlinear Dyn. 93, 611-627 (2018)

26. Wang, Z., Wang, X.H., Li, Y.X., Huang, X.: Stability and Hopf bifurcation of fractional-order complex-valued single neuron model with time delay. Int. J. Bifurc. Chaos 27(13), 1750209 (2017)

27. Li, L., Wang, Z., Li, Y.X., Shen, H., Lu, J.W.: Hopf bifurcation analysis of a complex-valued neural network model with discrete and distributed delays. Appl. Math. Comput. 330, 152-169 (2018)

28. Wang, Z., Li, L., Li, Y.Y., Cheng, Z.S.: Stability and Hopf bifurcation of a three-neuron network with multiple discrete and distributed delays. Neural Process. Lett. 48(3), 1481-1502 (2018)

29. Fan, Y.J., Huang, X., Wang, Z., Li, Y.X.: Improved quasi-synchronization criteria for delayed fractional-order memristor-based neural networks via linear feedback control. Neurocomputing 306, 68-79 (2018)

30. Long, Z.W.: Exponential convergence of a non-autonomous Nicholson's blowflies model with an oscillating death rate. Electron. J. Qual. Theory Differ. Equ. 2016, 41, 1-7 (2016)

31. Ockendon, J.R., Tayler, A.B.: The dynamics of a current collection system for an electric locomotive. Proc. R. Soc. Lond. Ser. A, Math. Phys. Sci. 322(1551), 447-468 (1971)

32. Song, X.L., Zhao, P., Xing, Z.W., Peng, J.G.: Global asymptotic stability of CNNs with impulses and multi-proportional delays. Math. Methods Appl. Sci. 39(4), 722-733 (2016)

33. Derfel, G.A.: On the behaviour of the solutions of functional and functional-differential equations with serveral deviating arguments. Ukr. Math. J. 34, 286-291 (1982)

34. Fox, L., Ockendon, D.F., Tayler, A.B.: On a functional-differential equations. J. Inst. Math. Appl. 8(3), 271-307 (1971)

35. Derfel, G.A.: Kato problem for functional-differential equations and difference Schrödinger operator. Oper. Theory, Adv. Appl. 46, 319-321 (1990)

36. Zhou, L.Q.: Novel global exponential stability criteria for hybrid BAM neural networks with proportional delays. Neurocomputing 161, 99-106 (2015)

37. Hien, L.V., Son, D.T.: Finite-time stability of a class of non-autonomous neural networks with heterogeneous proportional delays. Appl. Math. Comput. 251, 14-23 (2015)

38. Liu, B.W.: Global exponential convergence of non-autonomous SICNNs with multi-proportional delays. Neural Comput. Appl. 28(8), 1927-1931 (2017)

\section{Submit your manuscript to a SpringerOpen ${ }^{\circ}$ journal and benefit from:}

- Convenient online submission

- Rigorous peer review

- Open access: articles freely available online

- High visibility within the field

- Retaining the copyright to your article

Submit your next manuscript at $\boldsymbol{~ s p r i n g e r o p e n . c o m ~}$ 